\title{
Erratum: Study on rail fastener failure testing based on fractal theory
}

\author{
Huijian Zhang ${ }^{1}$, Qiang Liu ${ }^{2}$ \\ Beijing Municipal Institute of Labour Protection, Beijing, China \\ ${ }^{1}$ Corresponding author \\ E-mail: ${ }^{1}$ shuiyincy123@163.com, ${ }^{2}$ liuqiang347@126.com \\ DOI https://doi.org/10.21595/vp.2017.19334
}

Check for updates

\section{Publisher's note regarding paper}

Zhang Huijian, Liu Qiang Study on rail fastener failure testing based on fractal theory. Vibroengineering PROCEDIA, Vol. 14, 2017, p. 208-213, https://doi.org/10.21595/vp.2017.19171.

\section{The description of the correction}

The author's name was misspelled in the paper originally submitted and finally approved (after the acceptance) by the Authors.

Incorrect authors' list:

Huijian Zhang, Qiang Liu

Correct authors' list:

Huijuan Zhang, Qiang Liu 